\title{
RELASI FILOSOFIS ISLAM NUSANTARA DENGAN HINDU NUSANTARA DALAM HINDU TOLOTANG DI KABUPATEN SIDRAP SULAWESI SELATAN
}

\section{PHILOSOPHICAL RELATIONSHIP OF ISLAM NUSANTARA WITH HINDU NUSANTARA IN HINDU TOLOTANG AT SIDRAP DISTRICT SOUTH SULAWESI}

\author{
Shofiyullah MZ \\ UIN Sunan Kalijaga Yogyakarta, Indonesia \\ shofiyullah1001@gmail.com \\ Muhammad Alwi HS \\ UIN Sunan Kalijaga Yogyakarta, Indonesia \\ muhalwihs2@gmail.com \\ Zulfajri Amiruddin \\ UIN Sunan Kalijaga Yogyakarta, Indonesia \\ zulfajri132@gmail.com
}

Artikel diterima 8 November 2020, diseleksi 22 November 2020, dan disetujui 22 Desember 2020

\begin{abstract}
This study aims to discuss the philosophical relation of the persecution and developing traditions in Islam Nusantara and Hindu Nusantara. This departs from the thesis that religious humans can not be separated from the tradition that encloses, even though the tradition does not make him satisfied in religion. This research is a field study, which describes as well as analyzing sources obtained from the results of interviews, observation, and documentation of the Hindu Tolotang group in Kelurahan Amparita Sidrap Regency, South Sulawesi. The results of this study say that Hindu Nusantara and Islam Nusantara are both able to finalize his teachings with the context of human life he encountered. The results of religious dialogue and contexts read in this study include tradition in the form of worship and social, visit the cemetery, marriage, pay promises or nazar, and respect for the leader or kiai. These four traditions show philosophical relation with each in its context. This shows that many traditions of marketing awakening in Islam and Hindu are maintained through Islam Nusantara initiated by the Nahdlatul Ulama and
\end{abstract}

\begin{abstract}
Abstrak
Penelitian ini mendiskusikan relasi filosofis tradisi-tradisi yang berkembang dalam Islam Nusantara dan Hindu Nusantara. Hal ini berangkat dari tesis bahwa manusia yang beragama tidak dapat dipisahkan dari tradisi yang melingkupinya, sekalipun tradisi tersebut tidak membuatnya puas dalam beragama. Penelitian ini merupakan kajian lapangan, yakni melakukan wawancara, observasi, dan dokumentasi dari kelompok Hindu Tolotang di kelurahan Amparita kabupaten Sidrap, Sulawesi Selatan. Hasil penelitian ini mengatakan bahwa Hindu Nusantara dan Islam Nusantara keduanya mampu mendialogkan ajarannya dengan konteks kehidupan manusia yang ditemuinya. Adapun hasil dialog agama dan konteks yang terbaca dalam penelitian ini mencakup tradisi dalam bentuk ibadah dan sosial, yakni ziarah kubur, adat pernikahan, bayar janji atau nazar, dan hormat kepada pemuka atau kiai. Keempat tradisi tersebut memperlihatkan relasi filosofis dengan masing-masing pada konteksnya. Hal ini menunjukkan bahwa
\end{abstract}


Hindu Nusantara initiated Hindu Tolotang. This article also shows that there is an understanding of Islam Nusantara and Hindu Nusantara which assesses the fact that Indonesia is a multicultural, pluralistic country that brings together religion and local culture.

Keywords: Tradition, Islam Nusantara, Hindu Nusantara, Nahdlatul Ulama, Hindu Tolotang.

\section{PENDAHULUAN}

Jauh sebelum istilah 'Islam Nusantara' (tahun 2015) muncul, menyebar dan terkenal di Indonesia, telah lama muncul dan berkembang 'Hindu Nusantara' (tahun 1966) di Indonesia. Jika Islam Nusantara diprakarsai oleh salah satu kelompok Islam di Indonesia, yakni Nahdlatul Ulama (lihat Sahal, 2015), maka Hindu Nusantara diprakarsai oleh salah satu kelompok Hindu di Indonesia, yakni Hindu Tolotang yang biasa juga disebut Towani Tolotang. Mengenai Islam Nusantara, Said Agil selaku pimpinan Nahdlatul Ulama mengatakan bahwa melalui Islam Nusantara, umat Islam di Indonesia diharapkan mempertahankan jati dirinya, kepribadiannya sebagai umat Islam Indonesia yang berdasar Ahlussunnah wal Jama'ah, moderat dan berbudaya (Agil, 2016). Sementara Hindu Nusantara, Irman selaku kepala Kementrian Agama daerah SidrapSulawesi Selatan mengatakan bahwa sama seperti Islam Nusantara, Hindu Nusantara juga menganut paham dalam mempertahankan tradisi dan adatbudaya Sulawesi Selatan (Wawancara dengan Irman, 2018). Edi Slamet (Ua' Eja) selaku tokoh utama dalam Hindu Tolotang mengatakan bahwa Hindu Tolotang menjadi sekte dalam agama Hindu yang tetap melestarikan tradisi banyak tradisi kenusantaraan yang terjaga dalam agama Islam dan Hindu tetap terjaga melalui Islam Nusantara yang diprakarsai Nahdlatul Ulama dan Hindu Nusantara yang diprakarsai Hindu Tolotang. Artikel ini juga menunjukkan bahwa hadirnya pemahaman Islam Nusantara dan Hindu Nusantara memperkuat fakta tentang Indonesia sebagai negara yang multikultural, majemuk, yang mempertemukan agama dengan budaya lokal.

Kata Kunci: Tradisi, Islam Nusantara, Hindu Nusantara, Nahdlatul Ulama, Hindu Tolotang

dari nenek moyang hingga saat ini (Wawancara dengan Slamet, 2018).

Kemunculan Hindu Nusantara, berbeda dengan Islam Nusantara yang lahir dari ijtihad para ulama Nahdlatul Ulama untuk memberi warna bagi umat Islam di Indonesia. Hindu Nusantara merupakan hasil perubahan dari sebuah agama lokal menjadi salah satu sekte dari agama yang dilayani oleh negara, yakni agama Hindu. Perubahan dari sebuah aliran menjadi salah satu sekte agama Hindu ini didasari oleh Undang-undang Nomor 1/PNPS/1965 tentang Pencegahan Penyalahgunaan dan Penodaan Agama yang di dalamnya memuat pembatasan agama di Indonesia, sehingga agama yang dilayani negara hanya enam: Islam, Kristen, Budha, Konghucu, dan Hindu. Berdasarkan undang-undang tersebut, para tokoh aliran Towani Tolotang akhirnya mengadakan pertemuan dan menghasilkan kesepakatan bahwa Towani Tolotang memilih agama Hindu, hal ini mengikut keputusan Dirjen Bimas Hindu Balu/Budha No. 2/ 1966 (Fedyani, 2002).

Selanjutnya, dalam penelusuran penulis tentang kajian atas Islam Nusantara telah banyak penelitian yang mengkajinya, di antaranya yang dilakukan oleh Endan Soetari AD dan Sumadi 
(2019), Salamuddin (2019), Tri Wahyudi Ramdhan (2018), Tuti Munfaridah (2017), Ngatawi Al-Zastrouw (2017), Taufiq Bilfagih (2016), dan lain sebagainya. Namun, sepanjang penelusuran peneliti, fenomena Hindu Nusantara belum mendapat perhatian dari para peneliti, padahal Hindu Nusantara telah ada jauh sebelum Islam Nusantara. Selama ini, kajian yang banyak dilakukan hanya berkisar pada Towani Tolotang, sebagaimana yang dilakukan oleh Ahmad Mustanir dan Irfan Jaya (2016), Hasse J (2016), Alfiansyah, Mahmud Tang dan Safriadi (2018), dan lain sebagainya. Karena itu, artikel ini akan mengkaji Hindu Nusantara yang mencoba menganalisis dari segi relasi filosofisnya kepada Islam Nusantara, khususnya yang muncul dan berkembang dalam kehidupan masyarakat penganut Hindu Tolotang di kabupaten Sidrap, Sulawesi Selatan.

Lebih jauh, maksud dari relasi filosofis dalam penelitian ini adalah upaya menggali hubungan spirit ajaran Islam dan Hindu dalam mengakomodir tradisi masyarakatnya. Hal ini bertujuan untuk, minimal, memberi satu perspektif bahwa fenomena ajaran agama (teks) yang berdialog dengan tradisi lokal (konteks) pada dasarnya bukan hal asing, melainkan senantiasa ada dalam sejarah manusia yang beragama. Al Makin mengatakan bahwa agama selalu 'mendatangi' umat manusia secara kontekstual, yakni menyesuaikan dengan kehidupan manusia yang dihadapinya (Al Makin, 2016). Senada dengan pandangan ini, dikatakan juga bahwa orang yang beragama pada dasarnya sedang terikat kepada Yang Asal dan kepada alamnya (Nasr, 1981), sehingga tercipta manusia beragama dengan menciptakan kearifan lokal (Abdullah, 2008). Dari sini melahirkan pemahaman bahwa Indonesia adalah negara yang masyarakatnya majemuk, yang oleh Atho Mudzhar, lahir dari sifat multi dimensional yang muncul dari perbedaan suku, politik, agama dan sebagainya (Mudzhar, 2000).

Penelitian ini berfokus pada fenomena Hindu Nusantara yang dialami oleh penganut Hindu Tolotang di Amparita, kabupaten Sidrap, Sulawesi Selatan. Hal ini dikarenakan Amparita sebagai daerah yang menjadi pusat penyebaran Hindu Tolotang, yang juga sebagai tempat membedakan sekte Hindu Tolotang dengan sekte lainnya seperti Tolotang Benteng (Rusli, 2012). Titik tekan penelitian ini lebih diarahkan untuk menggali ajaran Hindu Tolotang tentang kenusantaraan pada ajaran-ajarannya, baik ibadah maupun sosial. Sementara itu, pembahasan tentang Islam Nusantara akan menjadi satuan analisis bersama Hindu Nusantara, hal ini berangkat dari asumsi bahwa kajian Islam Nusantara telah sangat marak dibahas di berbagai penelitian. Dengan kata lain, penelitian ini tidak akan membahas aspek definisi, sejarah, atau profil lainnya tentang Islam Nusantara, akan tetapi lebih berfokus pada ajaran-ajarannya, baik ibadah maupun sosial, yakni bagaimana tradisi lokal dan ajaran Islam saling berdialog berdasarkan Islam Nusantaran.

\section{METODE}

Penelitian ini merupakan penelitian lapangan sehingga mmenggunakan datadata lapangan seperti hasil wawancara, observasi dan dokumentasi, baik kepada para pemuka Hindu Tolotang, pihak Kementerian Agama Kabupaten Sidrap, lurah desa Amparita, pemuka agama selain Towani Tolotang, pengikut Towani Tolotang, maupun tiga orang dari kalangan masyarakat setempat. Berbagai data tersebut akan dianalisis secara deskriptif-analitis, yakni mendeskripsikan sekaligus menganalisis data-data yang terkumpul sehingga menemukan hasil yang holistik (Soehadha, 2012). Adapun langkah-langkah metodis dalam 
penelitian ini dibagi menjadi beberapa bahasan, pertama mengungkap sejarah singkat tentang Towani Tolotang, kedua mengungkap bentuk-bentuk dialog agama dan tradisi dalam pandangan Towani Tolotang yang membentuk Hindu Nusantara, ketiga mendiskusikan Hindu Nusantara dalam kacamata Islam Nusantara, keempat menemukan relasi filosofis atas tradisi-tradisi Islam Nusantara dengan Islam Nusantaran, dan kelima menarik kesimpulan atas berbagai analisis dari bahasan-bahasan sebelumnya.

\section{PEMBAHASAN}

\section{Profil Singkat Hindu Tolotang Sidrap}

Sebelum berafiliasi menjadi salah satu sekte agama Hindu, atau dikenal Hindu Tolotang, aliranini termasukagama lokal yang bernama Towani Tolotang yang berpusat di kabupaten Sidrap Sulawesi Selatan, tepatnya di kelurahan Amparita. Istilah Towani berasal dari nama salah satu kampung di kabupaten Wajo, sementara Tolotang terdiri dari dua kata berbahasa Bugis, yakni tao (orang), dan lotang (arah utara selatan). Dengan demikian, Towani Tolotang adalah penganut aliran Tolotang yang awalnya bermukim di kabupaten Wajo, kemudian berpindah ke kabupaten Sidrap, tepatnya di kelurahan Amparita pada abad 16 M (Syukur, 2015). Edi Slamet, selaku pemuka Towani Tolotang mengatakan bahwa pada abad 16 Masehi, Upa Bere' selaku pendiri Tolotang bersama para pengikutnya meninggalkan daerah Towani, kemudian masuk ke daerah Amparita. Riwayat masa perpindahan aliran ini dari towani ke amparita tidak diabadikan melalui tulisan, akan tetapi terus diwariskan secara penyampaian lisan (Wawancara dengan Slamet, 24 September 2018).

Sistem keyakinan Hindu Tolotang meyakini banyak Dewa, di mana Dewa tertinggi dalam keyakinan adalah Dewata
Seuwae. Dewata Seuwae berarti Dewa yang tidak berbentuk tetapi satu, hal ini serupa dengan konsep Tuhan Yang Esa dalam agama-agama monotheisme. Sementara dewa-dewa lainnya adalah Dewa Langie yakni dewa yang bersemayang di langit, dewa Mallinoe yakni dewa yang tinggal di bumi seperti di pohon, jalan, tanah dan sebagainya, dan dewa Uwae yakni dewa yang tinggal di dalam air (Iskandar, 2019). Selain itu, sekte Hindu Tolotang juga mempunyai empat kitab suci, yaitu pertama, Mula Ulo'na Batara Guru yang nmemuat keterangan tentang rencana Patotoe untuk menempatkan Batara Guru dibumi. Kedua Ritebbanna Walenrenge yang memuat cerita tentang keistimewaan kayu Walenrenge yang menjadi bahan pembuatan perahu oleh Sawerigading. Ketiga, $\mathrm{Ta}^{\prime}$ Gilina Sinapatie yang memuat cerita tentang perubahan situasi dunia. Keempat, Appaungenna Tolotange yang memuat berbagai keterangan tentang asal usul dan inti ajaran kepercayaan Tolotang (Mudzhar, 1985).

Selanjutnya, pada tahun 1965 pemerintah daerah -atas intruksi pemerintah pusat- tidak menginginkan adanya aliran kepercayaan selain lima agama besar di Indonesia, yakni Islam, Budha, Kristen, Konghuchu, dan Hindu (Hasse, 2010). Menanggapi intruksi tersebut, yang pada saat itu di bawah pemerintahan Soeharto, pemerintah daerah Sidrap menegaskan kepada seluruh masyarakat agar selain dari lima agama tersebut harus ditinggalkan, termasuk aliran Towani Tolotang. Menurut Edi Slamet, para penganut Towani Tolotang kemudian beralih dari aliran Tolotang masuk ke agama Hindu. Peralihan dari aliran Tolotang ke agama Hindu merupakan hasil perbincangan panjang yang dilakukan oleh para pemuka aliran Tolotang, sehingga aliran ini berubah yang dari Towani Tolotang menjadi Hindu-Tolotang (Wawancara dengan Slamet, 24 September 2018). 
Di atas perubahan dari Towani Tolotang menjadi Hindu Tolotang, menurut Edi Slamet bahwa para pemuka Tolotang, pemerintah beserta pihak pemuka Hindu bersepakat agar tidak akan mengganggu gugat apa yang telah menjadi tradisi dan adat dalam aliran Tolotang. Sehingga, sekalipun telah menjadi bagian agama Hindu, para penganut Tolotang tetap menggunakan tradisi dan adat istiadat, serta tetap menjalankan ajaran mereka sebagaimana saat masih berstatus Towani Tolotang. Edi Slamet mengatakan bahwa:

Jadi, namanya Hindu bermazhab Tolotang, sehingga tidak dipaksakan untuk membangun Pura, tidak dipaksakan untuk sembahyang, tetapi diwajibkan anak-anak kita yang sekolah di Makassar untuk di Pura (Wawancara dengan Slamet, 24 September 2018).

Berkenaan dengan kenyataan di atas, Irman selaku kepala Kementrian Agama daerah Sidrap mengatakan bahwa Hindu yang dipahami oleh penganut Tolotang memang berbeda dengan Hindu dari daerah lainnya. Irman menyamakan keadaan Hindu Tolotang tersebut dengan Islam di Indonesia. Ia mengatakan bahwa di dalam Islam di Indonesia sendiri juga terdapat pemahaman Islam Nusantara, yakni Islam yang mengakomodir tradisi dan budaya setempat. Dalam konteks ini -lanjut Irman- apa yang terjadi dalam agama Hindu Tolotang juga dapat dipahami sebagai Hindu yang senantiasa bertujuan untuk mempertahankan tradisi, adat dan budaya Sulawesi Selatan, bahkan tradisi yang tergambar dalam ajaran Hindu Tolotang itulah pada dasarnya tradisi Sulawesi Selatan yang sesungguhnya (Wawancara dengan Irman, 24 September 2018).

Dilihat dari segihubungan penganut Hindu Tolotang dengan masyarakat agama lainnya, penganut Hindu Tolotang termasuk dipandang sangat baik.
Hal ini misalnya dalam interaksinya dengan umat Islam di Amparita. Di daerah Ampirata, penganut Hindu Tolotang termasuk mayoritas dibanding masyarakat penganut agama lainnya, termasuk Islam. Irman, selaku kepala Kementrian Agama mengatakan bahwa penganut Hindu Tolotang mencapai 3000 jiwa di Amparita (Wawancara dengan Irman, 24 September 2018). Edi Slamet juga mengatakan bahwa masyarakat Hindu Tolotang mencapai $85 \%$ dari jumlah seluruh penduduk. Sementara yang lainnya, seperti umat Islam hanya berkisar 15\% (Wawancara dengan Slamet, 25 September 2018). Sekalipun presentasi kedua agama ini berbanding jauh, namun hubungan mereka terbilang sangat baik, bahkan dalam hal ibadah sekalipun. Misalnya dalam ritual ma'parinyamang (ziarah kubur), Edi Slamet mengatakan:

Bisa masuk. Cuman selama tidak masuk di kuburan. Jadi kita memang ada buat tenda khusus untuk tamu. Orang Bali banyak, ketua PHDI datang ke situ, tapi tidak masuk ke kuburan itu (Wawancara dengan Slamet, 25 September 2018).

Lebih jauh, penganut ajaran Hindu Tolotang juga kerapkali ikut merayakan hari raya umat Islam (Idul fitri dan Idul Adha), hal ini sebagaimana dikatakan oleh Jawad, selaku pengasuh pesantren di daerah Amparita:

Mereka ikut hari raya, hanya saja tidak ikut shalat 'Id, hanya sekedar ikut merayakan, tradisi di sini kan setelah hari raya adalah ziarah kubur, mereka lebih dahulu ziarah kubur, mereka juga membuat Burasa lebih dahulu. Pakaiannya mereka lebih Islami daripada orang Islam. Pakai Peci, Sarung dan pakai baju lengan panjang tapi bukan baju koko (Wawancara dengan Jawad, 24 September 2018).

Keterbukaan dan toleransi dari masyarakat penganut agama Hindu 
Tolotang telah diakui oleh masyarakat luas, berbagai kalangan menyebutkan bahwa mereka terkenal dengan sikap gotong royong dan keterbukaannya terhadap masyarakat lainnya. Jawad menceritakan bahwa dia memiliki teman seorang Tolotang yang setiap masuk waktu shalat, ia diingatkan untuk melaksanakan shalat oleh temannya yang beragama Hindu Tolotang tersebut (Wawancara dengan Jawad, 24 September 2018). Sangga'ati seorang Muallaf mengakui bahwa tidak ada keburukan sosial dalam Hindu Tolotang, secara sosial apa yang tergambar dari penganut Hindu Tolotang sangat baik, bahkan sangat dekat dengan ajaran Islam (Wawancara dengan Sangga'ati, 24 September 2018). Hal tersebut menunjukkan bahwa penganut agama Hindu Tolotang membangun relasi yang baik dengan masyarakat yang beragama lain, bahkan kepada orang yang telah keluar dari agamanya.

\section{Dialog Agama dan Tradisi dalam Hindu Nusantara}

Menurut Shils bahwa menusia tidak dapat lepas dari tradisi, manusia akan terus hidup dalam tradisi yang ada, sekalipun mereka tidak puas terhadap tradisinya (Sztompka, 2007: 74). Dalam konteks ini, para penganut Towani Tolotang menyebut dirinya sebagai salah satu sekte dari agama Hindu, yang tradisi, adat, dan ritual keagamaannya berbeda dengan sekte Hindu lainnya. Hindu Tolotang merupakan sekte dari agama Hindu yang berusaha mempertahankan tradisi dan adat yang selama ini berlaku dalam komunitasnya, hal ini menjadikannya dikenal sebagai Hindu Nusantara, yakni Hindu yang mempertahankan dan merangkul tradisi yang ditinggalkan oleh nenek moyang mereka (Wawancara dengan Irman, 24 September 2018). Fenomena ini dalam konteks beragama merupakan upaya mendialogkan ajaran agama dengan tradisi masyarakat. Lebih jauh, penulis menemukan beberapa tradisi Hindu Nusantara yang mendialogkan budaya dan Agama, yakni:

\section{a. Ziarah Kubur dalam Hindu Tolotang: Perrinyameng dan Batu Kiki}

Perrinyameng terdiri dari dua kata bahasa Bugis, yakni Perri yang berarti susah dan nyamang artinya senang. Di dalam Perrinyameng, terdapat beberapa aspek yakni aspek hubungan kepada Tuhan (Dewata Seuwae), hubungan kepada manusia, dan hubungan kepada Alam (Rusli, 2012). Dalam pemahaman lainnya, parinyamang merupakan nama daerah yang pertama kali didatangi oleh I $p a^{\prime}$ Bere, pendiri aliran Tolotang yang berasal dari Towani. Di tempat ini pulalah nenek moyang mereka di kuburkan, sementara kegiatan berziarah ke makam tersebut dikenal dengan istilah Mapperrinyameng. Kata ma yang terdapat pada awal parinyamang merupakan ungkapan yang menjadikan kata selanjutnya sebagai bentuk kata kerja. Dalam hal ini Ma'parinyameng dapat dipahami sebagai melakukan susah senang (Wawancara dengan Slamet, 24 September 2018).

Edi Slamet mengatakan bahwa sebelum wafat, Ipa' Bere berpesan kepada anak-cucunya untuk mengunjungi kuburnya sekali setahun. Kegiatan ziarah kubur setahun sekali ini disebut sebagai Sepulung, yakni berkumpul (Wawancara dengan Slamet, 25 September 2018). Dengan demikian, máparinyameng merupakan tradisi keagamaan Hindu Tolotang dengan melakukan sepulung di hadapan makam nenek moyang mereka, khususnya di makam Ipa' Bere sebagai tokoh pendiri aliran mereka. Setelah mereka melakukan ziarah kubur di Parinyameng, seminggu kemudian mereka mengadakan ziarah kubur ke daerah Batu Kiki. Tidak ada perbedaan dari cara ritual ziarah kubur yang dilakukan di parinyameng dan Batu Kiki, para penganut datang kemudian duduk, 
diam, dan menyiram air ke nisan makam. Tradisi ma'parinyameng dan Batu Kiki biasanya dilakukan pada bulan Januari. Akan tetapi tidak menutup kemungkinan terdapat perubahan jadwal apabila terdapat kendala yang signifikan, hal ini misalnya yang diutarakan oleh Ua' Jappi:

Tidak menutup kemungkinan, kayak kemarin ayahanda beliau (ua' batoa sekarang) meninggal, jadi acaranya diundur jadi bulan dua (Wawancara dengan Ua' Jappi, 25 September 2018).

b. Tradisi Pernikahan dalam Hindu Tolotang

Tradisi pernikahan dengan khas Bugis-Makassar adalah salah satu tradisi masyarakat yang dipertahankan dalam ajaran Hindu Tolotang. Adapun yang mencakup tradisi pernikahan BugisMakassar di antaranya ma'pituada yakni melakukan kesepakatan antara pihak keluarga laki-laki dan perempuan. Lalu Ma'pedupoddeng, yakni pemberian buahbuahan dari pihak laki-laki ke perempuan. Ketiga, Menre dina -sebutan laindari Uang Panaik, yakni pemberian uang dari pihak laki-laki ke perempuan (Lihat Yunus 2018; Juawini 2018). Mengenai Menre dina, terdapat batasan jumlah dalam tradisi Hindu-Tolotang, yakni jika itu keberadaannya dalam Hindu Tolotang sebagai rakyat biasa, maka uang yang diberikan maksimal 15 juta. Selain pemberian uang tunai, juga pemberian beras yang wajib dipenuhi dengan takaran hingga 3 kuintal untuk rakyat biasa, sementara untuk garis keturunan tokoh Hindu Tolotang sebanyak 8 Kuintal hingga 1 Ton (Wawancara dengan Slamet, 25 September 2018).

Perbedaan lainnya adalah pakaian pernikahan, di mana pakaian pernikahan Hindu-Tolotang dibedakan pakaian untuk rakyat biasa dengan tokoh pemuka Hindu-Tolotang. Untuk keluarga tokoh Hindu Tolotang memakai pakaian adat
Bugis-Makasar yang berwarna serba putih. Sementara untuk rakyat biasa memakai pakaian adat Bugis-makasar pada umumnya dengan warna selain putih (Wawancara dengan Ua' Jappi, 25 September 2018). Selain itu, yang paling khas dari adat pernikahan dalam Hindu Tolotang ini adalah proses akad nikah. Dalam hal ini, pengantin laki-laki dan perempuan dinikahkan oleh salah satu $U a^{\prime}$-penyebutan untuk pemuka Hindu Tolotang. Dalam akad tersebut, $U a^{\prime}$ menaruhkan ibu jari tangan pengantin laki-laki ke dahi perempuan, sehingga mereka telah sah menjadi suami-istri (Wawancara dengan Slamet, 25 September 2018).

Dalam konteks adat pernikahan ini, penganut Hindu Tolotang dapat menikah secara agama lain, seperti Islam, Kristen dan lainnya, dengan catatan bahwa mereka terlebih dahulu menikah secara adat dan ajaran Hindu Tolotang. Para penganut yang langsung menikah menggunakan ajaran agama lain, maka secara tidak langsung ia dikatakan pindah agama. Sementara itu, jika telah melakukan pernikahan dengan adat dan ajaran Hindu Tolotang, maka mereka dapat menikah dengan menggunakan adat dan ajaran agama lain (Wawancara dengan Slamet, 25 September 2018; lihat juga Eliza Meiyani, 2019).

\section{c. Bayar Janji di Parrinyameng}

Selain ziarah kubur, terdapat kegiatan lain yang dilakukan di parinyameng, kegiatan tersebut adalah Bayar Janji. Hal ini biasanya dilakukan oleh orang yang berjanji kepada Dewata Seuwai untuk urusan tertentu -yang sangat penting, maka janji tersebut wajib dipenuhi pada saat di Parinyameng. Hal ini sebagaimana dijelaskan oleh Edi slamet bahwa:

Kan kita di komunitas kita ada acara pak, seperti saya pak, DPR, di parinyameng ini kan sekali setahun. 
Tetapi tidak menutup kemungkinan antara bulan satu berjalan ke bulan satu tahun baru, untuk kita melepaskan hajat di situ. Contoh, DPRD terbang ke Jakarta misalnya atau ke Jogja, dalam perjalanan saya ke tempat itu, pesawat mengalami kendala, apa hujan apa petir, cuaca tidak bersahabat, maka di situlah saya timbul "ya Tuhan selamatkan kami dari tempat berangkat kami ke tujuan, dan tujuan ke rumah, selamatkan kami saya potong ayam 10". Jadi, sampai di rumah saya harus potong ayam 10 di parinyameng, di kuburannya Upa' Bere. Melepaskan hajat di situ, jadi tidak menutup kemungkinan ziarah kubur yang sekali setahun ini, saya ziarahi lebih, karena hajat (Wawancara dengan Slamet, 25 September 2018).

d. Hormat dari rakyat kepada pemuka dalam Hindu Tolotang

Dalam aliran Hindu Tolotang, rasa hormat kepada pemuka Tolotang menjadi hal yang mutlak dilakukan oleh setiap penganutnya. Bahkan rasa hormat inilah yang sangat menentukan nasib kemajuan dari aliran ini. Hal ini karena rasa hormat menjadi prinsip yang mengakar di kalangan penganut Hindu-Tolotang dari generasi ke generasi. Sikap hormat sangat erat kaitannya dengan keyakinan yang ada dalam diri penganutnya, dalam artian bahwa semakin taat si penganut maka semakin yakinlah dirinya. Prinsip hormat itu berbunyi "Tidak ada gunanya kamu yakin, jika kamu tidak takut. Dan tidak ada gunanya kamu takut, jika kamu tidak yakin." Hal ini sebagaimana yang diutarakan oleh Edi Slamet selaku pemuka aliran Hindu-Tolotang, ia mengatakan:

Ada satu prinsip orang Tolotang itu pak, kita tidak bisa hilangkan Hindu Tolotang itu, kita memang unik dari pesan orang tua, kalau bahasa
Bugisnya "Bone matappakko, kode' mutau, namutau kode' matappa (Sekalipun kamu takut kepada saya, tetapi tidak percaya dan yakin terhadap keyakinan kita ini, maka hal itu tidak ada gunanya. Sebaliknya, sekalipun kamu yakin, tapi jika tidak takut maka juga tidak ada gunanya)." Inilah pesan orang tua kita. Contohnya ini yah pak, tahun ini tahun politik, pilpres, caleg, kalau saya suruh kamu coblos yang ini tapi kamu tidak takut dengan saya, tidak ada juga gunanya (Wawancara dengan Slamet, 25 September 2018).

Berkaitan dengan ini Ridwan mengatakan bahwa para penganut (rakyat biasa) akan rela melakukan apapun demi ketataannya kepada pemuka Tolotang. Bahkan, mereka rela kehilangan nyawa sekiranya hal itu adalah permintaan pemuka Tolotang, hal ini sebagaimana diutarakannya:

Istilahnya kalau masyarakat di sini, kalo dia warganya, dan dia minta orang itu dipotong kepalanya, maka orang itu dipotong kepalanya di tempat. Saking taatnya mereka sama ua'nya (pemuka Tolotang). Artinya, ketaatan dan kepatuhan mereka kepada ua'nya sangat kuat.

Ketataan dalam aliran ini berdasarkan jabatan yang ditempatinya, dalam konteks ini, Ua' Batoa sebagai pemuka yang berkedudukan paling tinggi, kemudian ua'-ua' lainnya. Lebih jauh, para pengikut Hindu Tolotang tidak diperbolehkan untuk duduk sejajar dengan para ua'nya. Mereka para pengikut wajib merendahkan diri jika berhadapan dengan pemuka Tolotang. Hal ini sebagaimana dikatakan oleh Ridwan:

Pokoknya orang Tolotang itu pak, tidak ada jabatan yang kita miliki. Andaikalah saya danding, saya lepas dandingku baru saya masuk ke situ (Tolotang). Kesimpulannya saya bisa 
katakan, karena saya di sini, mereka terlahir dengan ketaatan. Mereka tidak akan bisa digoyangkan. Kenapa saya katakan, tadi sudah berapa yang menduduki jabatan strategis, masih menganut agama ini (Wawancara dengan Ridwan dan Istrinya, 23 September 2018).

Berkaitan dengan ini, istri Ridwan menambahkan bahwa:

Bahkan yang jendral yang dari Jakarta, yang di Bali, dia rela duduk di tanah, sementara ua'nya duduk di kursi. Pokoknya kalau dia di depan ua'nya tidak ada yang namanya tinggi pangkatnya atau gelar pendidikannya, semuanya duduk di bawah sementara ua'nya duduk di atas (Wawancara dengan Ridwan dan Istrinya, 23 September 2018).

\section{Hindu Nusantara Dalam Kacamata Islam Nusantara}

Munawir Abdul Fattah dalam bukunya Tradisi Orang-orang NU menyebutkan sangat banyak tradisitradisi Nahdlatul Ulama selaku kelompok penggagas Islam Nusantara, di antaranya tradisi dalam beribadah seperti mengucap Niat, do'a Iftitah, membaca do'a Qunut, dan sebagainya, dan tradisi dalam masalah sosial seperti jabat tangan setelah shalat, berjalan di kanan kiri nisan, membangun dan menghias makam, dan lain sebagainya (Fattah, 2006). Dari sini, bagian sebelumnya telah dibahas mengenai berbagai tradisi yang terdapat dalam sekte Hindu Tolotang, di sana dipahami bahwa berbagai tradisi tersebut ada yang secara bentuk tradisi ditemui dalam Islam Nusantara, ada juga yang secara fungsi atau tujuan ditemui dalam Islam Nusantara.

Pertama, Ziarah Kubur yang menjadi tradisi dalam Hindu Nusantara juga terdapat dalam tradisi Islam Nusantara.
Ziarah kubur di sini dipahami sebagai kegiatan mengunjungi pemakaman (Asnawi, 1996). Dalam Hindu Nusantara, ziarah kubur menjadi tradisi yang cenderung bersifat wajib. Hal ini dikarenakan berziarah di Parrinyameng dan Batu Kiki merupakan ibadah tahunan dalam Hindu Tolotang, sebagaimana pesan Ipa' Bere selaku pendiri Tolotang yang ingin agar kuburannya senantiasa diziarahi oleh para pengikutnya sekali setahun. Sementara dalam tradisi Islam Nusantara, ziarah kubur hanya bersifat boleh atau paling tinggi Sunnah, hal ini berdasarkan landasan dalam Islam bahwa ulama berdasarkan Al-Qur'an dan Hadis mengatakan bahwa ziarah kubur merupakan perbuatan yang memiliki banyak keutamaan (Subhani, 1995). Adapun hadis yang sering diungkap atas kebolehan Ziarah Kubur adalah "Dulu aku pernah melarang kalian berziarah kubur, sekarang berziarahlah kalian ke kuburan karena itu akan mengingatkan kalian pada akhirat" (HR. Muslim).

Kedua, tradisi pernikahan dalam Hindu Nusantara secara umum mengikuti tradisi pernikahan BugisMakassar, sekalipun terdapat catatancatatan tertentu. Dengan demikian, dapat dikatakan bahwa Hindu Nusantara mengadopsi dan menyesuaikan tradisi lokal Bugis-Makassar dengan ajaran Hindu Tolotang. Upaya ini juga terdapat dalam tradisi Islam Nusantara yang banyak mengadopsi dan menyesuaikan tradisi lokal dengan ajaran Islam (Syahid, 2019), termasuk pernikahan. Hal ini karena persoalan pernikahan merupakan bentuk muamalah, yang dapat diijtihadkan, yang bersifat lokalistik. Di Indonesia sendiri, tradisi lokal yang mengikuti pernikahan masyarakat lokal dikatakan masih banyak yang bertahan hingga saat ini (Casalba, 1976).

Pernikahan dalam agama hanya terletak pada akad pernikahan, akan tetapi, baik dalam Hindu Nusantara 
yang terlihat pada pengikut Hindu Tolotang maupun Islam Nusantara yang terlihat pada pengikut Nahdlatul Ulama, keduanya tidak berhenti sekedar akad. Misalnya, dalam Hindu Tolotang terdapat pemberian uang dari pihak laki-laki ke perempuan, di mana jika itu keberadaannya dalam Hindu Tolotang sebagai rakyat biasa, maka uang yang diberikan maksimal 15 juta rupiah. Selain pemberian uang tunai, juga pemberian beras yang wajib dipenuhi dengan takaran hingga 3 kuintal untuk rakyat biasa, sementara untuk garis keturunan tokoh Hindu Tolotang sebanyak 8 Kuintal hingga 1 Ton. Sementara dalam pernikahan Islam di Jawa misalnya, terdapat pemberian Sasarahan yang berupa binatang (Sapi atau Kerbau) dan Paningset yang berupa pakaian dan perhiasan dari pihak lakilaki kepada perempuan (Geertz, 2014). Fenomena semacam ini, menurut Purwadi, bahwa merupakan upaya manusia untuk memenuhi kebutuhan hidupnya (Purwadi, 2005).

Ketiga, Bayar Janji dalam Hindu Tolotang dapat dikaitkan dengan Nazar dalam tradisi Islam, termasuk Nahdlatul Ulama. Dalam website milik Nahdlatul Ulama, islami.nu.or.id, sebagaimana dalam tulisan M. Ali Zainal Abidin dijelaskan bahwa urusan yang dapat dilakukan melalui nazar adalah urusan yang bersifat sunnah atau Fardhu Kifayah seperti bernazar untuk bersedekah kepada fakir miskin, dan lain sebagainya, di mana urusan yang Sunnah atau Fardhu Kifayah akan menjadi wajib bagi orang yang bernazar (www.Islami.nu.or. id). Dengan pemahaman ini, bayar janji dalam Hindu Tolotang senada dengan Nahdlatul Ulama yang mewajibkan untuk membayarnya. Perbedaan dari keduanya terletak pada bentuk tradisinya, di mana pada Hindu Tolotang dilakukan wajib di Parrinyameng, sementara dalam tradisi Islam (Nahdlatul Ulama) tidak ditentukan tempat pelaksanaannya.
Keempat, rasa hormat dalam Hindu Tolotang juga dapat dikaitkan dengan ketundukan atau hormat ( $t a^{\prime} d z i m$ ) santri kepada kiainya, sebagaimana dalam tradisi kepesantrenan (Bashori, 2003). Dalam Hindu Tolotang, rakyat biasa diwajibkan dan mewajibkan dirinya untuk taat kepada pemuka sektenya, ketaatan tersebut berdasarkan dalam ungkapan "Bone matappakko, kode' mutau, namutau kode' matappa (Sekalipun kamu takut kepada saya, tetapi tidak percaya dan yakin terhadap keyakinan kita ini, maka hal itu tidak ada gunanya. Sebaliknya, sekalipun kamu yakin, tapi jika tidak takut maka juga tidak ada gunanya)." Sementara dalam tradisi Nahdlatul Ulama, khususnya santri atas kiainya, rasa hormat didasarkan pada pemahaman tentang kewajiban untuk ta'dzim kepada guru dalam kitab Ta'limul Muta'alim (Az-Zurnuji, 2009), yang di dalamnya dijelaskan bahwa seorang santri tidak akan mendapatkan ilmu yang bermanfaat kecuali dengan mengagungkan ilmu dan ahlinya. Namun, rasa hormat yang tinggi ini bukanlah berupa penyerahan diri sepenuhnya kepada kiai, melainkan sebagai bentuk penghormatan kepada kiai yang menjadi penyalur ilmu dari Tuhan (Karim, 2003).

\section{Relasi Filosofis Tradisi-tradisi Hindu Nusantara dan Islam Nusatara}

Sebelumnya telah dibahas bahwa berbagai tradisi Hindu Nusantara dapat dijumpai dalam tradisi Islam Nusantara, baik dari segi bentuk maupun fungsi atau tujuannya. Dari sini, melahirkan kesamaan dan perbedaan dalam tradisi Hindu Nusantara dengan Islam Nusantara. Kesamaan tersebut meliputi bentukbentuk tradisi, yakni tradisi Ziarah Kubur, Pernikahan, Bayar Janjji dan Kehormatan. Sementara perbedaannya adalah dilihat dari segi fungsi atau tujuan atas setiap tradisi-tradisi tersebut. Namun demikian, setiap tradisi dalam Hindu Nusantara 
dan Islam Nusantara membangun satu perspektif atas pentingnya pertemuan tradisi-tradisi dengan ajaran agama. Karena itu, bagian ini akan membahas pemetaan ajaran agama dengan tradisitradisi dalam Hindu Nusantara dan Islam Nusantara.

Pertama, Ziarah Kubur, baik dalam Hindu Nusantara maupun Islam Nusantara keduanya menganjurkan untuk melakukan ziarah kubur, di mana ziarah kubur tersebut untuk mengunjungi dan mendo'akan orangyang dihormatinya yang telah wafat tersebut. Dalam Hindu Tolotang, kewajiban untuk melakukan ziarah kubur di Parrinyameng dan Batu Kiki menunjukkan pentingnya kegiatan tersebut bagi penganut Hindu Tolotang. Selain itu, sifat wajib ziarah kubur ini juga memperlihatkan sejauhmana para pengikut Hindu Tolotang taat dan mengikuti pesan dari pendiri dan para pemuka Hindu Tolotang. Senada dengan Hindu Tolotang, ziarah kubur juga menjadi kegiatan penting bagi kalangan Nahdlatul Ulama. Kelompok Nahdlatul Ulama meyakini bahwa ada sangat hikmah dan manfaat dalam kegiatan ziarah kubur seperti mengingat kematian dan bersyukur atas keadaannya. Selain itu, sifat anjuran (Sunnah) ziarah kubur ini juga memperlihatkan sejauhmana para pengikut Nahdlatul Ulama senantiasa mengikuti hadis Nabi tentang kebolehan berziarah kubur.

Kedua, Tradisi Pernikahan, baik dalam Hindu Nusantara maupun Islam Nusantara keduanya mempertahankan dan mengadopsi budaya masyarakat yang dijumpainya, di mana sekalipun bagian pernikahan hanya terletak pada akad, tetapi masyarakat Hindu Tolotang dan Nahdlatul Ulama senantiasa menambahkan aspek budaya lokal pada acara pernikahannya. Hal ini menunjukkan bahwa selama budaya atau tradisi masyarakat tidak bertentangan atau mengabaikan akad sebagai bagian terpenting dalam pernikahan, maka dalam bentuk tradisi apapun dapat diterima. Misalnya, pemberian hadiah berupa Uang Panaik dan Beras dalam masyarakat Hindu Tolotang, dan sasarahan dan paningset dalam masyarakat Nahdlatul Ulama.

Ketiga, Bayar Janji atau Nazar, baik dalam Hindu Nusantara maupun Islam Nusantara keduanya mewajibkan pengikutnya untuk menunaikan janjinya, sekalipun berbeda mengenai lokasi pemenuhan janjinya. Kewajiban tersebut menunjukkan bahwa Hindu Tolotang dan Islam Nusantara memerhatikan relasi manusia dengan Yang Kuasa. Keduanya juga tidak menentukan bentuk nazarnya, dengan kata lain bentuk tradisinya mengikuti keadaan bagi orang yang bernazar. Dengan demikian, relasi nazar dalam Hindu Tolotang dan Islam Nusantara lebih menekankan pada aspek keyakinannya.

Keempat, rasa hormat, baik dalam Hindu Nusantara maupun Islam Nusantara keduanya menekankan perbuatan hormat kepada tokohtokoh kelompoknya. Dalam Hindu Nusantara, para pengikut ditekankan hormat kepada pemuka-pemuka (ua') Hindu Tolotang. Demikian juga Islam Nusantara yang menekankan santri atau masyarakatnya agar hormat kepada kiai-kiainya Nahdlatul Ulama. Hal ini menunjukkan bahwa kedua kelompok ini memerhatikan pentingnya menjaga sopan santun kepada pemuka agama, sebagai orang yang telah berpengaruh bagi dirinya terutama dalam menjalani pola hidup sebagaimana yang ditentukan ajaran kelompoknnya masing-masing.

Sampai di sini, berbagai paparan di atas memperlihatkan dua pehamanan dari kelompok agama, Islam dan Hindu, tentang sikap terhadap budaya dan tradisi masyarakat yang sudah ada senantiasa didialogkan dengan agama. Sehingga muncul sikap beragama

Jurnal Multikultural \& Multireligius Vol. $19 \mid$ No. 2 
yang moderat, mempertahankan nilai agama sembari mempertahankan tradisi dan budaya yang dianggapnya baik. Dengan demikian, paparan di atas setidaknya membuktikan bahwa agama selalu mendatangi manusia secara kontekstual, yang memperhatikan sifat alami manusia yang berbudaya. Dari sini kehadiran pemahaman Islam Nusantara dan Hindu Nusantara memperkuat fakta tentang Indonesia sebagai negara yang multikultural, majemuk, penuh keragaman baik dari segi agama maupun budaya lokalnya.

\section{SIMPULAN}

Dari berbagai pemaparan sebelumnya, maka dapat ditarik kesimpulan bahwa terjadi relasi filosofis dalam berbagai tradisi Hindu Nusantara dan Islam Nusantara. Berbagai relasi tersebutterdapatpadatradisiziarahkubur, pernikahan, bayar janji dan rasa hormat. Dengan demikian, Hindu Nusantara dan Islam Nusantara menjadi dua kelompok yang mampu mendialogkan ajarannya dengan konteks masyarakat yang dijumpainya. Sehingga, sekalipun telah berafiliasi dari aliran Towani Tolotang menjadi Hindu Tolotang, tetapi mereka masih mampu mempertahankan berbagai tradisinya. Dalam pandangan Islam Nusantara yang diprakarsai Nahdlatul Ulum, berbagai tradisi Hindu Tolotang memiliki kesamaan dari segi bentuk tradisinya dengan konteks keislaman. Hal ini menunjukkan bahwa budaya atau tradisi manusia tidak dapat dilepaskan bahkan ketika berhadapan dengan ajaran agamanya, sehingga lahir kearifan lokal dalam beragama dan berbudaya. Lebih jauh, hal ini juga menunjukkan bahwa banyak tradisi kenusantaraan yang terjaga dalam agama Islam dan Hindu tetap terjaga melalui Islam Nusantara yang diprakarsai Nahdlatul Ulama dan Hindu Nusantara yang diprakarsai Hindu Tolotang. Kehadiran pemahaman Islam Nusantara dan Hindu Nusantara memperkuat fakta tentang Indonesia sebagai negara yang multikultural, majemuk, penuh keragaman baik dari segi agama maupun budaya lokalnya. [] 


\section{DAFTAR ACUAN}

Abdullah, Irwan, dkk, (2008) Agama dan Kearifan Lokal dalam Tantangan Global, (Yogyakarta: Sekolah Pascasarjana UGM dan Pustaka Pelajar).

Abidin, M. Ali Zainal "Pengertian Nazar dan Ketentuannya dalam Islam" dalam http:// islam.nu.or.id/post/read/111231/pengertian-nazar-dan-ketentuannya-dalam, diakses pada 23 Juni 2020.

Al Makin, (2016). Keragaman dan Perbedaan: Budaya dan Agama dalam Lintas Sejarah Manusia, (Yogyakarta: SUKA Press).

Alfiansyah, Mahmud Tang dan Safriadi, "Perilaku Politik Towani Tolotang di Amparita Kabupaten Sidenreng Rappang", dalam jurnal Etnosia: Jurnal Etnografi Indonesia, Volume 2 Nomor 3, Desember 2018.

Al-Zastrouw, Ngatawi, "Mengenal Sepintas Islam Nusantara", dalam jurnal Hayula: Indonesian Journal of Multidisciplinary Islamic Studies, Volume 1 Nomor 1, Januari 2017.

Asnawi, Sibtu, (1996). Adab Tata Cara Ziarah Kubur, (Kudus: Menara).

Az-Zurnuji, Syeikh, Ta'lim Muta'allim, (2009). terj. Abdul Kadir Aljufri, (Surabaya: Mutiara Ilmu).

Bilfagih, Taufik, "Islam Nusantara: Strategi Kebudayaan NU di tengah Tantangan Global", dalam jurnal Aqlam: journal of Islam and Plurality, Volume 2 Nomor 1, Desember 2016.

Casalba, Sidi, (1976). Asas Kebudayaan Islam, (Jakarta: Bulan Bintang).

Fattah, Munawir Abdul, (2006). Tradisi Orang-orang NU, (Yogyakarta: Pustaka Pesantren).

Fedyani, Achmad dan Saefuddin, (2002). Agama dalam Politik Keseragaman, (Jakarta: Badan Penelitian dan Pengembangan Agama, Depertemen Agama RI).

Geertz, Clifford, (2014). Agama Jawa, Abangan, Santri, Priyayi dalam Kebudayaan Jawa, terj. Aswad Mahasin, (Depok: Komunitas Bambu).

Hasse J, “Dinamika Hubungan Islam dan Agama Lokal di Indonesia: Pengalaman Towani Tolotang di Sulawesi Selatan" dalam jurnal Wawasan: Jurnal Ilmiah Agama dan Sosial Budaya, Volume 1 Nomor 2, Juli 2016.

“Kebijakan Negara terhadap Agama Lokal “Towani Tolotang” di Kabupaten Sidrap, Sulawesi Selatan", dalam jurnal Studi Pemerintahan, Volume 1 Nomor 1, Agustus 2010.

Hidayat, Kamaruddin, "Pengantar", dalam Khoiruddin Bashori, (2003). Problem Psiokologis Kaum Santri: Risiko Insekuritas Kelekatan, (Yogyakarta: FkBA).

Iskandar, Jamaluddin, "Kepercayaan Komunitas Towani Tolotang" dalam jurnal AlTadabbur: Kajian Sosial, Peradaban dan Agama, Volume 5 Nomor 1, Juni 2019.

Juawini, M., “Nilai-nilai Moral dalam Ritual Adat Pernikahan Masyarakat Bugis dan Relevansinya dengan nilai-nilai Pendidikan Islam (Studi di Kecamatan Panca Rijang Kabupaten Sidrap), Tesis UIN Sunan Kalijaga Yogyakarta, 2018.

Karim, A. Gaffar dkk, (2003). Metamorfosis NU dan Politisasi Islam Indonesia, (Yogyakarta: Pustaka Pelajar). 
Meiyani, Eliza, "Perkawinan Toani Tolotang di Kabupaten Sidrap" dalam INA-Rxiv, Maret, 2019.

Mudzhar, Atho, (1985). "Mesjid dan Bakul Keramat", dalam Mukhlis dan Kathryn Obinson, (ed), Agama dan Realitas Sosial, (Ujung Pandang: Lembaga Penerbitan Universitas Hasanuddin).

(2001). Pendekatan Studi Islam dalam Teori dan Praktek, (Yogyakarta: Pustaka Pelajar).

Munfaridah, Tuti, "Islam Nusantara sebagai Manifestasi Nahdlatul Ulama (NU) dalam Mewujudkan Perdamaian", dalam jurnal Wahana Akademika, Volume 4 Nomor 1, April 2017.

Mustanir, Ahmad dan Irfan Jaya, "Pengaruh Kepimpinan dan Budaya Politik terhadap Perilaku Pemilih Towani Tolotang di Kecamatan Maritengngae Kabupaten Sidenreng Rappang" dalam jurnal Politik Profetik, Volume 4 Nomor 1, 2016.

Nasr, S.H., (1981) Tradisional Islam in The Modern Word, (Kuala Lumpur: Foundation for Traditional Studies).

Purwadi, (2005). Upacara Tradisional Jawa: Menggali Untaian Kearifan Lokal, (Yogyakarta: Pustaka Pelajar).

Ramdhan, Tri Wahyudi, "Islam Nusantara: Pribumisasi Islam ala NU”, dalam jurnal AlInsyiroh: Jurnal Studi Keislaman, Volume 2 Nomor 1, Maret 2018.

Rusli, Muh., "Kearifan Lokal Masyarakat Towani Tolotang di Kabupaten Sidenren Rappang" dalam jurnal Al-Ulum, Volume 12 Nomor 2, Desember 2012.

Sahal, Ahmad dan Munawir Aziz (ed), (2015). Islam Nusantara: dari Ushul Figh hingga Konsep Historis, (Bandung: Mizan Pustaka).

Said Agil dalam kanal Youtube "164 Channel" tentang "Mengapa Islam Nusantara", dipublikasikan pada tanggal 24 Maret 2016. Diakses pada 12 September 2018.

Salamuddin, "Meneguhkan Islam Nusantara: Nahdlatul Ulama dan Falsafah Pendidikan Pesantren Musthafawiyah", dalam journal of Contemporary Islam and Muslim Societies, Volume 3 Nomor 1 Januari 2019.

Soetari, Endang AD dan Sumadi, "Islam Nusantara and Islamic Education: Dialogue Between Two Traditions" dalam jurnal Religious Studies: an International Journal, Volume 7 Nomor 1, 2019.

Subhani, Syekh Ja'far, (1995). Tawassul Tabarruk Ziarah Makam Karamah Wali: Kritik Sanad atas Faham Wahabi, (Bandung: Hidayah).

Syahid, Achmad,(2019). Islam Nusantara: Relasi Agama-agama dan Tendensi Kuasa Ulama, (Depok: Rajawali Press).

Syukur, Nur Ahsan, "Kepercayaan Tolotang dalam Perspektif Masyarakat Bugis Sidrap", dalam jurnal Rihlah, Volume III Nomor1, Oktober 2015.

Sztompka, Piotr, (2007). Sosiologi Perubahan Sosial, terj. (Jakarta: Pernada Media Group).

Undang-undang Nomor 1/PNPS/Tahun 1965 tentang Pencegahan Penyalahgunaan dan/ atau Penodaan Agama. 
Wawancara dengan Edi Slamet di ruangan kantor DPRD Kabupater Sidrap, pada tanggal 24 September 2018.

Wawancara dengan Edi Slamet di rumah Ua' Batoa, pada tanggal 25 September 2018.

Wawancara dengan Irman di ruangan kantor Kementrian Agama Kabupater Sidrap, pada tanggal 24 September 2018.

Wawancara dengan Jawad di Asrama Pondok Pesantren DDI As-Salman Sidrap, pada tanggal 24 September 2018.

Wawancara dengan Ridwan dan istrinya di rumah beliau, pada tanggal 23 September 2018.

Wawancara dengan Sangga'ati di ruangan rumah beliau, pada tanggal 24 September 2018.

Wawancara dengan Ua' Jappi di rumah Ua' Batoa, pada tanggal 25 September 2018.

Wawancara dengan Ua' Jappi di rumah Ua' Batoa, pada tanggal 25 September 2018.

Yunus, "Bugis dalam Islam dan Budaya (Nilai-nilai Islam dalam Proses Pernikahan Masyarakat Bugis)" dalam jurnal Titian: Jurnal Ilmu Humaniora, Volume 2 Nomor 1, Juni 2018. 